03

\title{
Влияние изменения газодинамической разгрузки на лазерное инициирование композита ТЭН-алюминий
}

\author{
( Б.П. Адуев, Д.Р. Нурмухаметов, А.А. Звеков, И.Ю. Лисков, Г.М. Белокуров, Н.В. Нелюбина \\ Институт углехимии и химического материаловедения Федерального исследовательского центра угля и углехимии \\ $\mathrm{CO} \mathrm{PAH}$, \\ 650000 Кемерово, Россия \\ e-mail: lesinko-iuxm@yandex.ru
}

(Поступило в Редакцию 12 июля 2017 г. В окончательной редакции 4 сентября 2018 г.)

\begin{abstract}
Экспериментально измерены зависимости порогов взрывчатого разложения $H_{c r}$ для тетранитрата пентаэритрита (ТЭН) с включениями наночастиц алюминия $(100 \mathrm{~nm})$ в диапазоне концентраций $0.05-1$ mass.\% при воздействии первой гармоники импульсного неодимового лазера $(14 \mathrm{~ns})$, а также амплитуды оптикоакустического сигнала в зависимости от концентрации включений в образце при фиксированной плотности энергии лазерного излучения. Исследовано два случая: первый - облучаемая поверхность образца накрывается стеклянной пластиной, препятствующей газодинамической разгрузке своим весом; второй к стеклянной пластине приложено внешнее давление $\geq 10^{7} \mathrm{~Pa}$, блокирующее газодинамическую разгрузку образца. Дано объяснение наблюдаемым эффектам, подкрепленное модельными теоретическими расчетами.
\end{abstract}

DOI: 10.21883/JTF.2019.02.47065.2471

\section{Введение}

Лазерное инициирование бризантных взрывчатых веществ (ВВ) давно привлекает внимание исследователей [1-6]. Одной из важнейших характеристик является порог инициирования ВВ. Эта характеристика зависит от многих факторов: дисперсности ВВ, плотности образцов, длины волны лазерного излучения, длительности импульса, наличия инородных включений и т.д. [1].

Однако следует учитывать один немаловажный фактор - лазерное инициирование взрыва тетранитрата пентаэритрита (ТЭН) достигается только в случае, когда облучаемая поверхность накрыта прозрачной подложкой, которая препятствует газодинамической разгрузке образца, создавая в области реакции повышенное давление [1]. Если целью является достижение минимального порога взрыва ВB, то фактор газодинамической разгрузки становится едва ли не самым важным. В связи с этим в [7] указывается необходимость описания условий эксперимента и поддержание их одинаковости для однозначной интерпретации результатов.

В настоящей работе исследовались пороги взрывчатого разложения ТЭН с различными концентрациями включений ультрадисперсных частиц алюминия при воздействии первой гармоники излучения $\mathrm{YAG}: \mathrm{Nd} 3^{+}$-лазера, при различных условиях газодинамической разгрузки.

\section{Методика и эксперимент}

В качестве источника инициирования использовалась первая $(\lambda=1064 \mathrm{~nm})$ гармоника YAG : Nd3 ${ }^{+}$-лазера, работающего в режиме модулированной добротности с длительностью импульса $\tau=14$ ns. Распределение интенсивности излучения по сечению пучка было близким к прямоугольному. Максимальная энергия в импульсе на основной частоте $E=1.5 \mathrm{~J}$. Изменение энергии производилось с помощью нейтральных светофильтров.

Для изготовления экспериментальных образцов использовался порошок ТЭН с узким гранулометрическим распределением. Размер зерен в максимуме распределения составлял $1-2 \mu \mathrm{m}$. Образцы изготавливались методом прессования в медном держателе, в центре которого имелось отверстие диметром $3 \mathrm{~mm}$. Плотность образцов составляла $\rho=1.73 \mathrm{~g} / \mathrm{cm}^{3}$. Использовались образцы, изготовленные из ТЭН с включениями $\mathrm{Al}$ 0.05-1 mass.\% и размером частиц в максимуме распределения $100 \mathrm{~nm}$. Методика изготовления и отбора образцов подробно изложена в работах $[8,9]$.

Поверхность образца, на которую воздействовало излучение, накрывалась стеклом для предотвращения

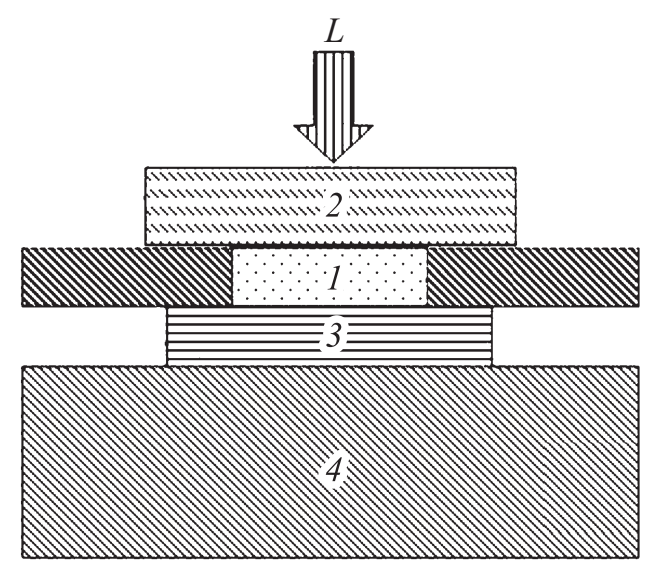

Рис. 1. Схема экспериментальной ячейки: 1 - медная пластина с впрессованным образцом, 2 - стеклянная пластина, 3 - пластина-свидетель, 4 - массивное основание, $L-$ лазерный импульс. 


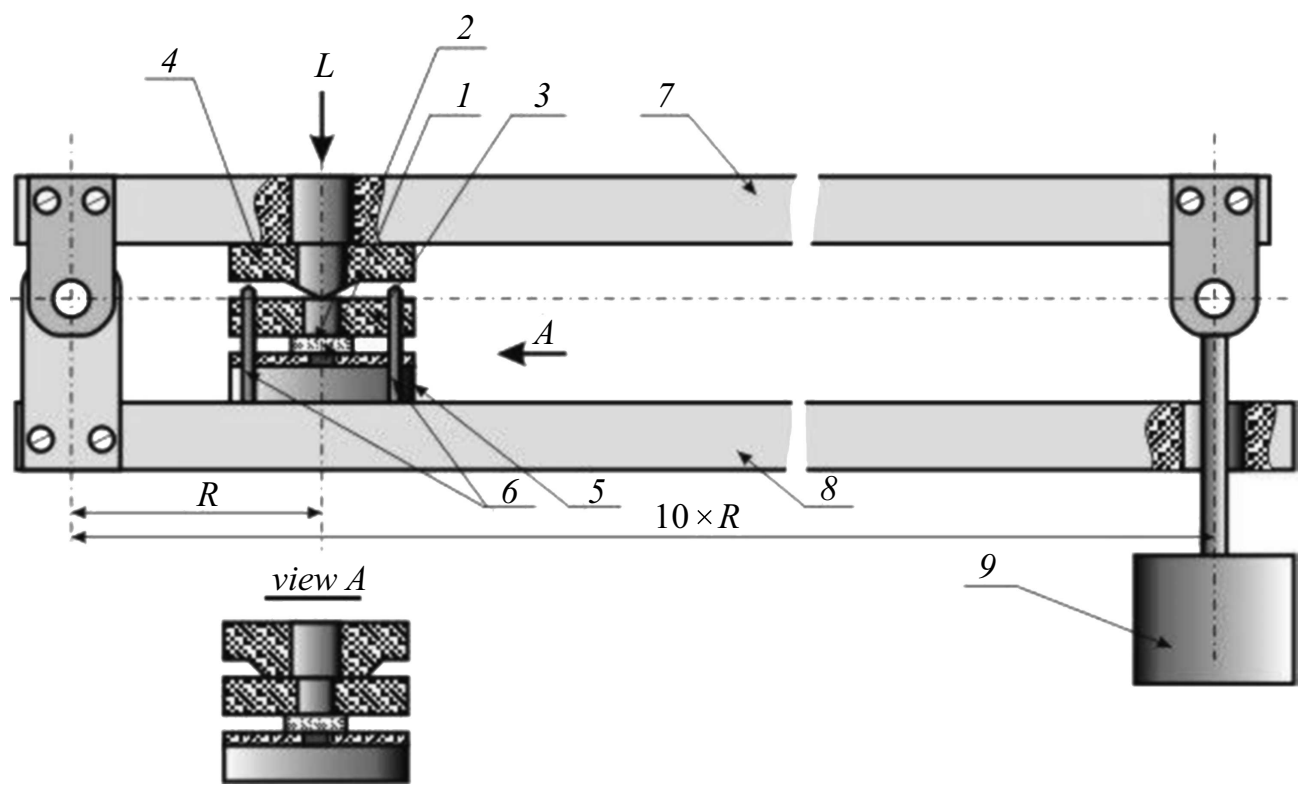

Рис. 2. Схема механизма, блокирующего газодинамическую разгрузку: 1 - образец, впрессованный в подложку, $2-$ стекло, $3-$ прижимная матрица, 4 - упор, 5 - опорная матрица, 6 - направляющие, 7 - рычаг, 8 - опора, $9-$ подвешиваемый груз, $L$ - лазерное излучение, $R$ - плечо рычага.

газодинамической разгрузки. Проводилось два типа экспериментов. В первом использовалась ячейка, представленная на рис. 1 . В данном виде ячейки образец в медной пластине 1 накрывался стеклянной пластиной 2 из оптического стекла К-8 толщиной $2 \mathrm{~mm}$ и помещался на пластину-свидетель из дюралюминия 3 , которая находилась на массивном стальном основании 4. Особенность - стеклянная пластина 2 лежит на образце, и газодинамическая разгрузка определяется весом пластины (нежесткая граница образец-стекло).

На рис. 2 приведена схема механизма, позволяющего увеличить усилие прижатия стекла размером $7 \times 7 \mathrm{~mm}$ к поверхности медной пластины с образцом. Облучаемая поверхность образца находилась ниже поверхности медной пластины на $0.1 \mathrm{~mm}$, что исключает приложение внешнего давления на образец. Блокирование газодинамической разгрузки определялось улучшением контакта стекло-медная пластина в результате приложения внешнего давления. Усилие зависит от величины груза 9, подвешиваемого на рычаг. Без груза вес рычага составляет $7.8 \mathrm{Kgf}$. Давление грузом 9 усиливается десятикратно плечом рычага $(R)$.

За факт взрыва, инициированного лазерным воздействием, принимался громкий звуковой сигнал и отпечаток на пластине-свидетеле, равный диаметру образца. Измерялись кривые частости взрыва для каждой концентрации включений. За порог взрыва, как и в других работах [8-10], принималась критическая плотность энергии $-H_{c r}$, соответствующая $50 \%$ вероятности взрыва.

\section{Результаты и обсуждение}

Результаты экспериментов для зависимости пороговой плотности энергии инициирования взрыва $H_{c r}$ от концентрации включений $n$ представлены на рис. 3 . В первом случае с использованием экспериментальной ячейки рис. 1 была получена кривая 1 . Во втором случае с использованием экспериментальной ячейки рис. 2 на сборку с образцом накладывался рычаг и подвешивался груз массой $8 \mathrm{~kg}$, что создавало на пластину с образцом давление $17.5 \cdot 10^{6}$ Ра. Наблюдается заметное уменьшение порога взрывчатого разложения (кривая 2). Это свидетельствует об ухудшении условий газодинамической разгрузки за счет улучшения контакта покровного стекла и медной пластины, в которую запрессован образец.

Минимальные пороги $H_{c r}$ на кривых 1 и 2 (рис. 3) составили 0.7 и $0.3 \mathrm{~J} / \mathrm{cm}^{2}$ соответственно, и находятся при одинаковых концентрациях включений алюминия $n=n_{i} \approx 0.2$ mass.\%, однако при возрастании ее выше оптимальной поведение кривых резко различается. Если на кривой 1 наблюдается резкий рост порога с увеличением $n$, то на кривой 2 возрастание порога слабо выражено.

Был проведен дополнительный эксперимент с увеличением нагрузки на стеклянную пластину до $42 \cdot 10^{6} \mathrm{~Pa}$ (масса подвешиваемого груза $20 \mathrm{~kg}$ ). Результат - кривая 3 на рис. 3, которая практически совпадает с кривой 2. Таким образом, в условиях эксперимента возможности уменьшения газодинамической разгрузки исчерпываются при давлении на стеклянную пластину $\geq 10^{7} \mathrm{~Pa}$. 


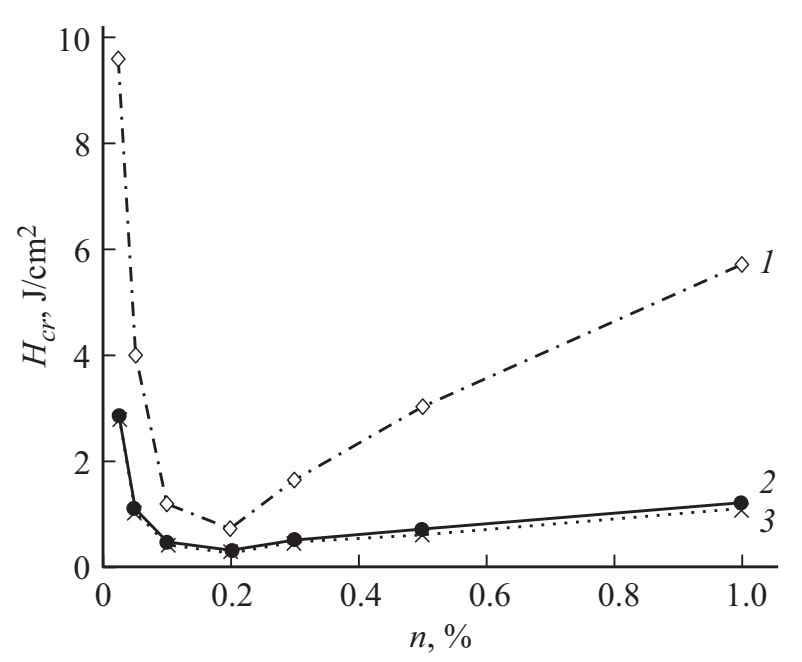

Рис. 3. Зависимости порога инициирования $H_{c r}$ от массовой доли включений $\mathrm{Al}: 1-$ с использованием ячейки рис. $1,2-$ с использованием ячейки рис. 2 , масса груза $8 \mathrm{~kg}, 3-\mathrm{c}$ использованием ячейки рис. 2, масса груза $20 \mathrm{~kg}$.

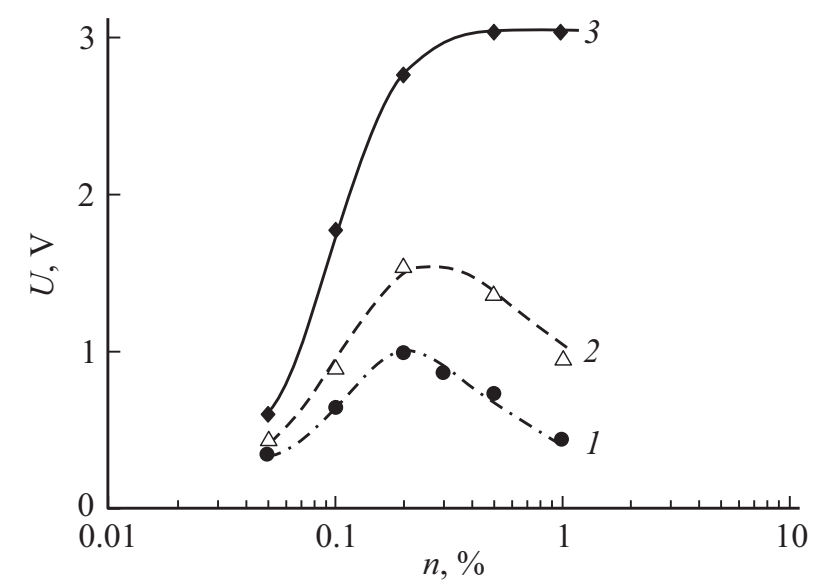

Рис. 4. Зависимость амплитуды сигнала с пьезопреобразователя от концентрации включений алюминия в образце: $1-$ при открытой облучаемой поверхности образца, 2 - при накрытой облучаемой поверхности образца стеклянной пластиной без приложения нагрузки, 3 - при накрытой облучаемой поверхности образца стеклянной пластиной с приложенной к ней нагрузкой $P=17.5 \cdot 10^{6} \mathrm{~Pa}$.

Для понимания хода зависимости $H_{c r}(n)$ была проведена еще одна серия экспериментов с использованием для детектирования пьезокерамического преобразователя. Стеклянная пластина убиралась, и воздействие лазерных импульсов производилось на открытую (свободную) поверхность образца. Образец находился в акустическом контакте с пьезопреобразователем, сигнал с которого, возникающий в результате воздействия лазерного импульса, регистрировался осциллографом LeCroy WJ332A. Отметим, что при воздействии на свободную поверхность образцы не взрываются. Измерялась амплитуда сигнала $U$ в зависимости от концентрации включений $n$.
Результаты представлены на рис. 4 (кривая 1). Зависимость $U(n)$ имеет характер кривой с максимумом, причем концентрация включений $n=0.2$ mass.\%, при которой наблюдается максимум сигнала с пьезопреобразователя $U$, совпадает с $n_{i}$, соответствующей минимальному порогу $H_{c r}$ на рис. 3.

В следующем эксперименте облучаемая поверхность накрывалась стеклянной пластиной и проводились аналогичные измерения. Отметим, что в этих экспериментах происходил взрыв образцов, однако первый по времени сигнал пьезопреобразователя от прошедшего через образец лазерного излучения позволил произвести необходимые измерения. Результат представлен на рис. 4, кривая 2, которая имеет аналогичный характер с кривой 1 . На кривой 2 наблюдается увеличение амплитуды сигнала относительно кривой 1 , однако концентрации $n_{i}$ имеют одинаковые значения.

Аналогичный эксперимент проведен с образцами под нагрузкой, т.е. в условиях, соответствующих получению кривой 2 на рис. 3. Результат представлен на рис. 5. В этом случае с ростом концентрации включений наблюдается рост сигнала пьезоакустического преобразователя до значения, стремящегося к стационарному.

Для качественной интерпретации полученной зависимости проведены расчеты амплитуды давления, возникающего при воздействии на вещество с теплофизическими параметрами ТЭН лазерных импульсов с длительностью $14 \mathrm{~ns}$ при варьировании показателя поглощения излучения. Использована модель оптоакустического эффекта в жидкости [11], согласно которой кинетика изменения оптоакустического сигнала определяется выражением:

$$
\begin{aligned}
P(t) & =\frac{k c_{s}^{2} \beta H}{4 c_{p}} \exp \left(\frac{\left(k c_{s} \tau_{L}\right)^{2}}{4}\right) \\
& \times\left\{\frac{(1-N)}{(1+N)}\left[2-\operatorname{erfc}\left(\frac{t}{\tau_{L}}-\frac{k c_{s} \tau_{L}}{2}\right)\right] \exp \left(-k c_{s} t\right)\right. \\
& \left.+\operatorname{erfc}\left(\frac{t}{\tau_{L}}+\frac{k c_{s} \tau_{L}}{2}\right) \exp \left(k c_{s} t\right)\right\}
\end{aligned}
$$

где $P(t)$ - давление, $c_{s}=2500 \mathrm{~m} / \mathrm{s}-$ скорость звука в ТЭН $[12], \beta=2.32 \cdot 10^{-4} \mathrm{~K}^{-1}-$ коэффициент термического расширения [13], $c_{p}=2.22 \mathrm{~J} / \mathrm{cm}^{3}-$ объемная теплоемкость [13], $H=0.1 \mathrm{~J} / \mathrm{cm}^{2}-$ плотность энергии импульса, $\tau_{L}=7.2 \mathrm{~ns}-$ половина длительности импульса на уровне $1 / e$ амплитуды, $N=\left(1-R_{a}\right) /\left(1+R_{a}\right)-$ акустический импеданс границы, $R_{a}-$ коэффициент отражения акустической волны от границы (по амплитуде скорости или давления), который определяется выражением:

$$
R_{a}=\frac{c_{s}^{\prime} \rho^{\prime}-c_{s} \rho}{c_{s}^{\prime} \rho^{\prime}+c_{s} \rho}
$$

где $\rho=1.77 \mathrm{~g} / \mathrm{cm}^{3}$ и $\rho^{\prime}=2.33 \mathrm{~g} / \mathrm{cm}^{3}-$ плотности ТЭН и стекла соответственно, $c_{s}^{\prime}=5640 \mathrm{~m} / \mathrm{s}-$ скорость звука в стекле [14]. 


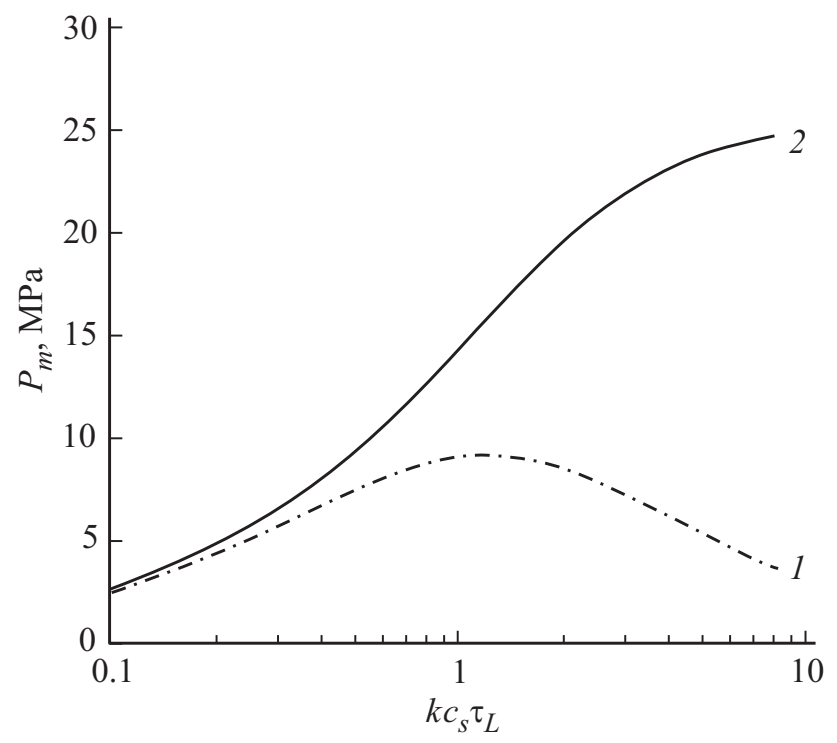

Рис. 5. Расчетная зависимость амплитуды давления в оптоакустической волне от безразмерного показателя поглощения: 1 - для свободной границы, 2 - для жесткой границы образец-стекло.

Рассчитанные амплитудные значения давления в зависимости от величины $k c_{s} \tau_{L}$ показаны на рис. 5. В эксперименте $c_{s}$ и $\tau_{L}$ постоянны, поэтому характер зависимости $P_{m}\left(k c_{s} \tau_{L}\right)$ определяется изменением показателя поглощения $k$, который однозначно связан с концентрацией включений [12]. Формирование максимума на зависимости $P_{m}(k)$ (рис. 5, кривая 1 ) объясняется конкуренцией двух эффектов. При увеличении показателя поглощения возрастает объемная плотность поглощенной энергии импульса, что приводит к росту давления благодаря первому множителю в уравнении (1). По мере увеличения $k$ толщина слоя, в котором поглощается энергия излучения, уменьшается. В результате уменьшается время его механической релаксации и становится заметным расширение вещества во время действия импульса, что приводит к уменьшению давления. Максимум, показывающий границу между областями преобладания первого и второго эффектов, наблюдается при значении безразмерного параметра $k c_{s} \tau_{L}=1.2$ (рис. 5). При $k c_{s} \tau_{L} \ll 1.2$ реализуется режим быстрого, „мгновенного“ нагрева без релаксации давления во время действия импульса. В противоположном пределе $k c_{s} \tau_{L} \gg 1.2$ термическое расширение поглощающего слоя с толщиной $k^{-1}$ позволяет ему „подстроиться“ под повышение температуры, что приводит к уменьшению амплитуды давления. Отметим качественное согласие экспериментально полученных данных (рис. 4) и рассчитанных в рамках модели (рис. 5). Это позволяет считать границу образец-стекло в экспериментах, представленных на рис. 3 (кривая 1), почти свободной.

Из проведенных экспериментов следует, что при нарушении условия „мгновенного“ возбуждения при свободной (или почти свободной) границе амплитуда давления в результате поглощения энергии лазерного импульса падает (рис. 5). Это требует увеличения плотности энергии для инициирования ТЭН, что приводит к росту $H_{c r}$ при увеличении концентрации включений $n>n_{i}$ на рис. 3 , кривая 1 .

На рис. 5 представлены результаты расчета для жестко закрепленной границы образец-стекло (рис. 5, кривая 3). В этом случае происходит движение волны вглубь возбуждаемого вещества без его расширения, соответственно максимальное давление стремится к стационарному значению, которое диктуется процессом акустической релаксации слоя. В результате при увеличении концентрации включений (соответственно показателя поглощения $k$ ) изменение амплитуды давления практически прекращается.

Необходимо отметить, что при моделировании для кривой 2 рис. 5 использовалось приближение идеального акустического контакта, которое выполняется с точностью до шероховатости поверхностей.

Типичные значения шероховатости стекол и металлов - порядка нескольких микрон. При прижатии стеклянной пластины к образцу контакт должен улучшаться, однако будет оставаться неидеальным. В случае идеального контакта следовало ожидать, что $H_{c r}$ на рис. 3 (кривые 2 и 3 ) будет иметь минимальное значение при достижении $P \approx$ const на рис. 5. Однако неидеальность контакта при проведении эксперимента, повидимому, приводит к уменьшению амплитуды давления в области высоких значений показателя поглощения относительно рассчитанной кривой на рис. 5. В связи с этим на рис. 3 (кривые 2 и 3) при превышении некоторого оптимального значения $n_{i}$ с дальнейшим ростом концентрации включений вместо минимального стационарного значения наблюдается слабый рост $H_{c r}$, после превышения оптимальных концентраций $n_{i}$.

\section{Выводы}

1.Измерены пороги взрывчатого разложения $H_{c r}$ в зависимости от концентрации включений Al для двух случаев. 1) облучаемая поверхность накрывалась стеклянной пластиной; 2) стеклянная пластина нагружалась давлением $17.5 \cdot 10^{6} \mathrm{~Pa}$.

2. Значение оптимальной концентрации включений $n_{i}$, при которой $H_{c r}$ минимально, одинаково при нагруженной и ненагруженной стеклянной пластине, однако прилагаемое давление ведет к ослаблению газодинамической разгрузки образца и уменьшению $H_{c r}$.

3. Границу образец-стекло без приложения дополнительной нагрузки можно считать практически свободной, а при приложении нагрузки $>10^{7} \mathrm{~Pa}-$ жестко закрепленной.

4. Совокупность результатов позволяет объяснить на качественном уровне зависимости $H_{c r}$ от концентрации включений в обоих случаях. 
Исследование выполнено в рамках программы Фундаментальные научные исследования (ГП 14) по теме V.49.1.5., рег. ном. АAАA-A17-117041910150-2.

\section{Список литературы}

[1] Быстрое инициирование ВВ. Особые режимы детонации / Сб. научн. статей под ред. В.И. Таржанова. Снежинск.: Изд-во РФЯЦ-ВНИИТФ, 1998. 168 с.

[2] Ng W.L., Field J.E., Hauser H.M. // J. Appl. Phys. 1986. Vol. 12. P. 3945.

[3] Aluker E.D., Krechetov A.G., Mitrofanov A.Y., Nurmukhametov D.R., Kuklja M.M. // J. Phys. Chem. C. 2011. Vol. 115. N 14. P. 6893-6901.

[4] Yang Y., Sun Z., Wang S., Dlott D. // J. Phys. Chem. B. 2003. Vol. 107. N 19. P. 4485-4493.

[5] Иофбе В.Б., Долголаптев А.В., Александров В.Е., Образцов А.П. // Физика горения и взрыва. 1985. Т. 21. № 3. C. 51.

[6] Кригер В.Г., Каленский А.В., Звеков А.А., Зыков И.Ю., Адуев Б.П. // Физика горения и взрыва. 2012. Т. 48. № 6. C.54-58.

[7] Александров Е.И., Вознюк А.Г., Ципилев В.П. // Физика горения и взрыва. 1989. Т. 25. № 1. С. 3-9.

[8] Адуев Б.П., Нурмухаметов Д.Р., Ципилев В.П., Фурега Р.И. // Физика горения и взрыва. 2013. Т. 49. № 2. C. $102-105$.

[9] Адуев Б.П., Белокуров Г.М., Нурмухаметов Д.Р., Нелюбина Н.В. // Физика горения и взрыва. 2012. Т. 48. № 3. C. $127-132$.

[10] Адуев Б.П., Нурмухаметов Д.Р., Звеков А.А., Никитин А.П., Каленский А.В. // Физика горения и взрыва. 2016. T. 52. № 6. C. 104-110.

[11] Гусев В.Э., Карабутов А.А. Лазерная оптоакустика М.: Наука, 1991. 304 с.

[12] Адуев Б.П., Нурмухаметов Д.Р., Фурега Р.И., Лисков И.Ю. // Химическая физика. 2014. Т. 33. № 12. C. 29-32.

[13] Олинджер Б., Кейди Г. Ударная сжимаемость ТЭНа, ТАТБ, $\mathrm{CO}_{2}$ и $\mathrm{H}_{2} \mathrm{O}$ при давлениях до 10 ГПа, рассчитанная на основании экспериментальных данных по гидростатическому сжатию. В сб. статей „Детонация и взрывчатые вещества“ / Под ред. А.А. Борисова. М.: Мир, 1981. C. 203-219.

[14] Tables of Physical \& Chemical Constants (16th edition 1995). Kaye \& Laby Online. Version 1.0 (2005)

www.kayelaby.npl.co.uk 